\title{
How Too much Emphasis on Connectivity is Decelerating the Exploitation of Digital Content in Poor Countries
}

\author{
Leonard J. Mselle, Tabu S. Kondo \\ Department of Computer Science, The University of Dodoma \\ Dodoma, Tanzania
}

\begin{abstract}
In this paper we describe how an Offline Personal Learning Environment (OPLE) for learning mathematics was implemented in Tanzanian secondary schools. We argue that too much emphasis on connectivity has decelerated the use of digital content for education in poor countries like Tanzania.
\end{abstract}

\section{Introduction}

Evidence suggests that technology can reduce cost, improve student performance and tailor the learning process to the like of individual students. In order to stay competitive, schools should strive to offer education through digital means. This is the idea behind the "New Paradigm Initiative" through which, a group of 16 liberal-arts colleges in the America have joined together to offer online and hybrid courses to students on any campus in the group [1]. While the concept of use of technology in education is vigorously been pursued in developed countries the case is different in poor countries.

\section{Learning styles overview}

Learning styles can be defined as unique manners in which learners begin to concentrate on, process, absorb, and retain new and difficult information [2]. They are distinctive individual patterns of learning, which vary from person to person. It is necessary to determine what is most likely to trigger each learner's concentration, how to maintain it, and how to respond to his or her natural processing style to produce long term memory and retention.

It is argued that knowing your learning style enables you to use your strengths as you study for courses. One of many instruments for determining learning style is the VARK questionnaire, developed by Neil Fleming [3]. The VARK system categorizes learners into four groups: Visual, Aural, Reading/Writing, and Kinesthetic. Many learners show strength in more than one learning style.

Visual learners learn best from visual images that do not include writing. Graphs and diagrams are easy for them to understand. They remember faces and places and tend to recall information by picturing it in their minds. If you want to invite a visual learner to come to your house, draw a map. In college, a visual learner is going to find it relatively easy to "read" a pie chart in a business class or perceive differences between artists' painting styles.

Aural or auditory learners do well with hearing information. They remember words to songs and can recall conversations in detail by hearing them in their minds. If you want an aural learner to come to your house, just tell him or her how to get there. In college, an aural learner will remember lecture materials in a variety of classes and may be skilled at memorizing things like music or lines for a theatrical production.

Reading/Writing learners are at home with written material. They comprehend and remember what they read, and they often enjoy writing. If you want a reading/writing learner to come to your house, provide written directions. College classes have traditionally been geared to the reading/writing learning style; these learners can take notes in most classes and will benefit from reading them as a method for study.

Kinesthetic learners learn by doing. Hands-on activities and real-life experiences help them remember. If you want a kinesthetic learner to come to your house, the simplest way is to take him or her there yourself or get someone else to do so. Another way to give directions to a kinesthetic learner would be to provide details about what to look for on the way there, making your directions as experiential as possible. College classes like science labs, acting, or sports teach to the strengths of kinesthetic learners [3].

Any content in digital format can be presented in various forms (image, text, voice, and animation). In education, since digital content can be presented in multiple forms, then digital format should have enjoyed preference over conventional formats.

\subsection{Digital content in education}

Digital content can be defined as that content which is accessed through electronic devices such as computers, digital readers etc. Digital content for educational purposes, can mainly be accessed either 
offline (locally) or online or in combination of both. As far as education is concerned, what matters most is the availability of the content more than how it reaches the learner.

\subsection{Online vs. offline digital content}

Independent of its form and format, digital content can be accessed from a storage device which may be part of the machine being used for reading. This is what is termed as locally accessed content. Locally accessed content can be from external peripheral storages or from the embedded storage device within the machine. In whatever case locally accessed content is offline. Alternatively, digital content can be read from a computer located (meters/kilometers) away from the machine used by the reader. The two machines must be connected through wires or antennae. In this case such content is termed as online.

Often, there are cases where, the reader connects his/her machine to a remote source, download the material to a local device and access the downloaded content offline. This arrangement cannot be termed as purely offline. In this case, electronic devices such as computers, televisions, mobile phones, or any other device of similar capabilities can be used.

Digital content, local/offline or online empowers teachers by enabling them to spread their knowledge and experience in various places at an instance without being there physically. Digital content enables teachers to re-use their past works without much change while facilitating them to combine their works with materials prepared by superior peers. Similarly, digital content, local/offline or online enables students who have no books, lack competent teachers, have no access to libraries, etc to use any of their learning style to pursue their studies more flexibly and more successfully.

Since digital content can be presented in different forms, it is more amenable to different learning styles for different students.

\section{Problem definition}

The tendency to categorize local digital content obtained online as offline has contributed to too much emphasis on connectivity with regards to the use of digital content in schools. This has had adverse (deceleration) effect on the proliferation of digital content in general. This warped focus has contributed in elevation of connectivity to a primary position in digital content delivery, while undermining other means of delivery such as Compact Discs (CDs), flash disks, etc. Such misdirection has denied the users of digital content the opportunity of using such content offline with its benefits. Among the groups which could benefit from the use of local/offline digital content is the Tanzanian secondary schools.

The present secondary school education system in Tanzania is in a dire situation. The average ratio of students to teacher is very high (120:1). More than $70 \%$ of students complete their secondary school studies without having a reference book. For mathematics and science subjects, teachers are available only for $20 \%$ of the entire study period. This is manifested in a general poor performance for secondary school students. For example, in the year 2012/2013 only $43.08 \%$ of Form IV students passed the Form IV (ordinary level) secondary school examinations [4]. Due to overemphasis on connectivity, the advantages of using offline digital content in places where it is most needed have not been fully exploited. Most governments and educationists are waiting for connectivity in order to start using digital content in their schools.

\section{Objectives}

The main objective of this paper is to demonstrate how overemphasis on connectivity has adversely impacted the use of ICT in Tanzanian secondary schools. To attain this objective first we demonstrate;

i. the acceptability of digital approach in learning mathematics by students of different cadre with and without computer knowledge.

ii. acceptability of digital approach in teaching mathematics among teachers of different cadre regardless of their computer knowledge.

iii. viability/feasibility of deploying digital learning approach in Tanzanian secondary schools.

\section{Research questions}

i. To what extent will digital approach be accepted by students in Tanzanian secondary schools?

ii. To what extent will digital approach be accepted by teachers in Tanzanian secondary schools?

iii. How is offline digital approach in teaching mathematics viable/feasible in the current Tanzanian context?

\section{The OPLE model}

The OPLE model as proposed in figure 1 is a three-legged stool resting on the student, the teacher/digital content expert/facilitator and the technology (ICT) that delivers digital content. This combination revolves on a digital content developed by a subject expert who depends on the technology to reach the students. The technology infrastructure is expected to serve fundamentally as an enabler in the proposed model, revitalizing and refreshing practice in teaching and learning. In this model, we advocate the use of offline digital content because 
connectivity is still embryonic in Tanzanian schools. This model is designed for the purpose of demonstrating how offline digital content can play a more or less similar role as the online digital content.

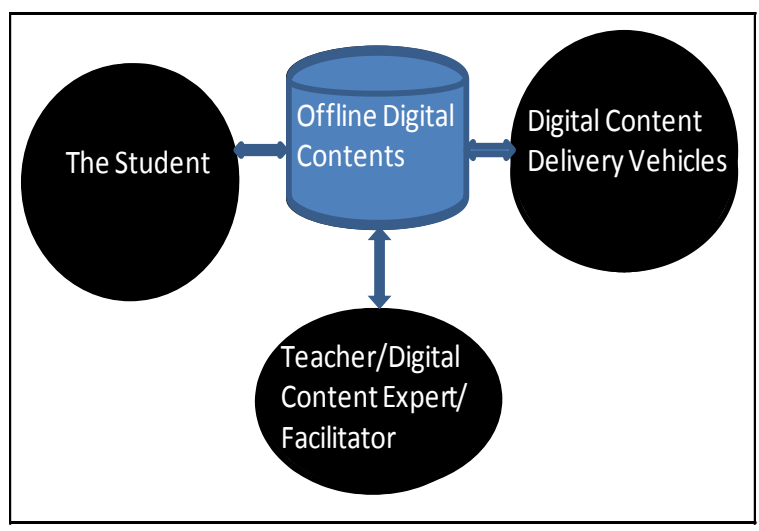

Figure 1. The OPLE model

\subsection{The students}

ICT increases the student's involvement and motivation in the learning process. Johns et al [5] suggest that proficiency in computer-based multimedia is an important skill for students who use the Internet on a fairly regular basis. However, Mselle and Kondo [6] found that computer skills are not a necessary condition for students to use offline digital content for their studies. There is growing evidence that digital lectures can be just as useful as face-to-face lectures if the environment is created.

Since the content delivered offline is as useful as that delivered online, internet connectivity and internet-related skills are not a necessary condition for students to use the OPLE.

In this research we found four cases in one district in Tanzania where a school is without a mathematics teacher for an entire period of three years in the four years life-span of a student. We found six cases where a single teacher was struggling with a class of more than 140 students. There were two instances in which the only mathematics teacher available in a school was transferred to another school or had to leave the school abruptly, leaving students without a teacher for an indefinite time. This situation in Tanzania is rather a norm than an exception. Under such circumstances, the burden that a student must bear is beyond normal. Assistance from a digital teacher, if available, is expected to mitigate the impact of the total lack of teachers and other learning facilities. As discussed earlier, digital content is likely to be more user friendly to students due to its multifaceted nature.

\subsection{Digital teacher, the subject expert and the facilitator}

In an ideal situation, the OPLE depends on a digital teacher aided by a teacher who is an expert of the subject and a facilitator who is not necessarily required to be expert in the field of ICT or in the subject matter that he/she is supposed to facilitate. If circumstances do not permit, the digital content can be delivered without a facilitator or a subject expert.

\subsection{Digital content delivery vehicles (the ICT)}

Apart from connectivity, the primary delivery vehicles for digital content are computers, televisions and mobile phones. Peripherals such as CD-ROMs, DVDs and DVD players are additional tools used for offline delivery. The Personal Learning Environment (PLE) under ideal conditions includes the intranets and internet connectivity, satellite and web broadcasts of classes and conferences, mobile phones, other handheld devices (e.g. PDAs, MP3 players, i-pods, digital audio recorders, and digital video recorders), games consoles, televisions and radios. In our case the conditions were far from ideal. As a result we resorted to offline digital content which was delivered in DVDs, with and without teachers and in some cases without facilitators.

\section{The need for integrating ICT in teaching and learning activities}

The rapidly growth of ICT has brought great changes in every sphere of life, education included. This calls for a paradigm shift towards the role of teacher from being knowledge transmitter into the role of a mentor, guide and manager of the learning process in the classroom while more responsibilities are placed to learners themselves [7].

In a survey of 300 primary and 100 secondary Scottish schools in UK, William [8] found that the impact of integrating ICT equipment in learning activities is positive and more than $60 \%$ of the teachers and students were of this view.

Ficheman and Lopes [9] contend that using new technology for learning may enhance the students learning interest and motivation since it enables students to learn outside the classroom, and it is easy to use. Today's students engage in learning activities in different spaces, time and situations. These can therefore be supported by digital content, which can be used anywhere, anytime, and in any environment, whether the learner is alone or in groups.

Bassili [10] conducted a study on college freshmen in a psychology course in order to determine whether they preferred face-to-face or streamed-video lectures as a learning aid. He found 
that the majority of the students preferred online video lectures.

Mselle and Kondo [6] carried out a study on secondary school students in mathematics course and found that students preferred offline video lectures to face-to-face approach.

\section{The effectiveness of using ICT in teaching and learning activities}

It is believed that using new technology for learning may enhance the students' learning interest and motivation since it is easy to use. Digital content enables students to learn within and outside the classroom [9].

Students have different learning levels, learning preferences and styles, which may be addressed on an individual basis by digital technologies, thereby enhancing learning. The technology uses different types of (multi) media; text, videos, audios, among others and therefore addresses the different learners interests, needs, goals, preferences, styles and motivation [11].

Greenberg [12] points out three advantages of using videos to teach: interactivity with content, engagement, and knowledge transfer and memory. He contends that videos combine various types of data-format such as images, motion, sound and text. Learning can be adjusted more easily to the diverse learning styles and the individual pace of learning. With video content, the learner controls the information delivered and he/she has additional opportunity of being able to stop, rewind, fast forward and replay content as many times as needed.

\section{The experiment}

Deployment of digital content in Tanzanian secondary schools is a new phenomenon. So far there is no national or local plan on how this new approach can be used to mitigate the acute lack of teachers and books. To ascertain the viability of using digital approach in secondary schools, three privately owned and one public secondary school were randomly selected for the experiment. A total of 18 mathematics teachers, with 9 digital-content assistants and 2 administrators were invited to participate in the experiment.

\section{Description of schools and students}

The first school, School A, located in Bagamoyo, 2 kilometers from Dar es Salaam is privately owned. School A is exclusive for girls. Using National Examinations Council of Tanzania (NECTA) results of 2012/2013, School A is ranked 81st among 3396 schools in Tanzania [13]. A total of 687 Form I, Form II, Form III and Form IV students studying mathematics were involved in the experiment. 12 mathematics teachers from School A were invited to participate. In addition 6 assistants (non mathematics teachers) were enlisted as digital facilitators.

The second school, School B, located in Songea Rural, 800 kilometers from Dar es Salaam is owned by Hanga Monastery of Songea. School B is a mixture secondary school. In 2012/2013 NECTA results, School B is ranked 220th among 3396 schools [13]. A total of 320 Form I, Form II, Form III and Form IV students studying mathematics were involved in the experiment. 3 mathematics teachers from School B were invited to participate. In addition three assistants (non mathematics teachers) were enlisted as digital facilitators. For School B this experiment was a repetition with modification of using facilitators in collaboration with teachers. However, before the experiment had started the teachers declined the invitation [9].

The third school, School C, located in Moshi Rural 650 kilometers from Dar es Salaam is owned by the Catholic Diocese of Moshi. Using the 2012/2013 NECTA results, School C is ranked 270th among 3396 schools in Tanzania [13]. A total of 160 Form I, Form II, Form III and Form IV students studying mathematics were involved in the experiment. 3 mathematics teachers from School C were invited to participate. Since there were no digital assistants available in School C, the teachers were requested to facilitate.

The fourth school, School D, located in Moshi Rural 641 kilometers from Dar es Salaam is owned by the Local District Council of Moshi Rural District. Using the 2012/2013 NECTA results, School D is ranked 981st among 3396 secondary schools [13]. A total of 12 Form III and Form IV students studying mathematics were involved in the experiment. No mathematics teachers from School D were invited to participate. There were no digital assistants available. In their place, two students were trained to use the content and assist others as the need might arise.

\section{Procedure}

In the case of School A and School B, the administration agreed to participate in the implementation of an eight week campaign to use digital approach in teaching and learning mathematics. Computer laboratories were availed for students, teachers and facilitators. Teachers were instructed to learn and use the content as it might deem fit for them. Students were briefed of the campaign to use digital content for learning mathematics. Digital content assistants were responsible for collecting written students' views which were compiled after a period of eight weeks of the campaign. 
In the case of School $\mathrm{C}$, the teachers were responsible for determining when and how digital content could be deployed. The school administration was not involved. After one term, these teachers were asked to provide their views regarding the viability of digital approach and students' reactions.

In the case of School D, two students (without special characteristics) volunteered to determine when and how to use digital content for self study. One week latter, they were joined by four colleagues. Because these students had no computers, a domestic television and DVD player were used for content deployment. After six months of using digital videos for self study the responsible students were asked to provide their views regarding the viability of digital approach in studying mathematics.

An open ended questionnaire and observations were used to collect data regarding:

1. Acceptability of digital content among teachers

2. Acceptability of digital content among students

3. Feasibility of deploying digital content within the limitations of specific schools.

Students from School A and School B anonymously jotted down comments regarding video content. They were guided by two key words, that is; strengths in learning through video content and weaknesses of the approach. Teachers gave their opinions verbally and individually. In case of School C, teachers provided their observations and students' reactions. In case of School D, students were interviewed.

\section{Summary of the findings}

The majority of students were of the opinion that digital content was very useful. All teachers agreed that despite its limitations, digital content was useful. It should be noted that, although not all students had access to computers, the presence of local digital content in more than 25 machines in a remote School constituted a digital library of huge importance.

Compared with paper materials, the digital content was deployed for free and with tremendous ease. For comparison, if we had attempted to donate 50 books, to these schools it would have cost not less than Tsh 1,000,000.00 (USD 750) if we assume that one copy is obtained at Tsh 20,000 (USD 15)

During our experiment, in School D for example, where teachers and books were not available, students' frequency of using digital content was 10 hours in a week. For School $\mathrm{C}$ the reported frequency was negligible. In the case of School A the frequency recorded was 4 hours a week, this being the time allotted for compulsory self study. For
School B the frequency recorded was 5 hours, this also being the compulsory time allotted for self study. Notwithstanding these frequencies, it is evident that locally stored digital content is highly acceptable by both students and teachers in Tanzanian schools.

\section{Acceptability of digital content among students and teachers}

The acceptability of digital approach by students and teachers is indisputable. Students were absolutely in support of the method both in their comments and in observation. This validates findings by Ficheman and Lopes [9] and Greenberg [12]. Except for the issues of quality of recording for some videos and lack of opportunity to ask the digital expert questions and clarification, all students were positive about the acceptability of the digital approach.

In the case of School D, it was demonstrated that digital content became the savior of students who were without teachers and books. The availability of a digital content/teacher dramatically increased the frequency of study from the average of 3 hours per week to an average of 10 hours per week.

In general, all teachers who agreed to participate were supportive of digital content in their comments. This again validates findings by Ficheman and Lopes [9] and Greenberg [12].

\section{Offline vs. online weirdness}

At the surface, the tendency of intimately linking digital content with the Internet has had negative repercussions. In educational realm, linking digital content so intimately with the Internet has resulted into a narrow perception of the former, jeopardizing its spread and its adoption in teaching and learning. This narrow perception of digital content has contributed into;

- Lack of sufficient emphasis on the use of locally accessible ebooks and other digital materials for offline learning.

- Lack of sufficient effort to develop and use offline digital content for teaching and learning for secondary schools, specifically in poor countries where good teachers are scarce, books are not available, classes are huge and connectivity is not available.

This notion is so ingrained to the extent that even most definitions pertaining to offline digital content are impossible without linking them with the Internet. Such definitions often consider offline digital content to be that one residing at a local device such as computer, after being downloaded from the Internet through connectivity. The typical example is the one captioned below: 
Offline digital content refers to cached pages from the Internet so that the user can load those pages quicker the next time they are visited [14].

Such definition omits the fact that a teacher can develop digital content, record it in offline media such as hard disks and CDs and make use of such content just as any other digital material can be used through the web. This narrow view of digital content is extended to the perception of offline digital library, ebooks, etc.

In this work, we define offline digital content to include any content that is distributed and accessible even without connectivity, so long as it is portable in digital media such as CDs, magnetic disks, etc.

Narrow view of digital content is detected even in some useful digital platforms such as Moodle which have had a huge impact in infusing learning through digital content by intimately linking it to the Internet to the extent that most of its description gyrates on connectivity as demonstrated by the following passages;

What is Moodle and why use it?

Moodle is a Virtual Learning Environment (VLE) which enables individuals to pursue learning outside "motor and bricks" classroom environment. Moodlebased courses take place in the web environment where students and staff can access a set of tools and resources anytime anywhere to carry on their studies

Moodle is credited with ability to facilitate online communication and materials sharing between instructors and students, whereby instructors and students can exchange notes, opinions, quizzes, assignments, etc during the course-run. Peers also can exchange ideas, documents and points of view as way of collaborative learning through Moodle.

Moodle is used by instructors to record their lectures as podcasts posting these online and making it available to students in a straight forward way.

Learning is best carried out when it can be pursued anytime anywhere at the like of the learner. In a way, the Internet, as a learning platform, provides the ideal environment for learning anytime anywhere and even anyhow. Web-based learning environments such as Moodle have been successful, thanks to the Internet.

However, while excellent facilities like Moodle in offline mode would have been a good idea to experiment, there is minimum effort towards this direction. In the meantime there is a lot of emphasis on connectivity and the Internet. It is high time to imagine of sub-Moodles outside the Internet.

\section{The viability of deploying digital content within the limitations of specific countries and schools}

Although in Tanzania connectivity is still embryonic, electricity still erratic and there is a general lack of content experts, the country and schools can rely on the freely available digital content and offline approach to mitigate the negative impact of absolute lack of teachers and books. Most of digital content available in the Internet is made by experts who are specialized in the subject and in teaching it. The digital content scored very high marks from both students and teachers. Research on how deployment of offline digital content can be accelerated, particularly in poor countries like Tanzania are of paramount importance.

\section{Conclusions and recommendations}

Use of digital content locally and offline as proposed in OPLE model can mitigate the impact of severe scarcity of books and teachers just as contended by Ficheman and Lopes [9] and Greenberg [12]. Even in those places where connection exists; locally readable digital content should not be neglected.

So far, there exists a twisted perception that all digital content of useful character should be accessed from a remote site.

Paradoxical as it may seem, digital approach is more successful in the situations where teachers and books are nonexistent.

Digital content obtained from various sites in the internet do not need connectivity for effective deployment at the end user side. Content can be downloaded once be effectively shared offline in different places where connectivity is not present. This reinforces findings by Mselle and Kondo [6]. To be able to exploit digital content in all its form and format, it is necessary to accept that digital content can be spread and can be deployed without the Internet connectivity at the consumption point. It is important to appreciate that what is important is the availability of content to the reader and not the way it reaches him/her.

There is urgency for more research on other variables such as students' learning styles in the framework of digital content. Variables pertaining to how specific subjects are better suited to specific category of students in the realm of digital content need to be investigated. It is useful to conduct research on how best a combination of face-to-face method with digital content can be attained.

\section{References}

[1] http://www.ecu.edu/cs-admin/news/clips/upload/062712.pdf. (22 September 2012)

[2] Dunn, R., Dunn, K., and Freeley, M. E. (1984) "Practical applications of the research: responding to students' learning styles-step one", Illinois State Research and Development Journal, 21(1), pp. 1-21.

[3] Fleming, N. D. (2001) Teaching and Learning Styles: VARK Strategies, ISBN 0-473- 07956-9, Honolulu Community College. 
[4] http://www.moe.go.tz/index.php?option=com_docman\&task $=$ doc_details\&Itemid=0\&gid=212 (20 June 2013).

[5] Jones, V., Jo, J., and Crantich, G. "A study of students' responses to WBI within a traditional learning environment", The sixth Australian World Wide Web Conference, retrieved from http://ausweb.scu.edu.au/aw2k/papers/jones/paper.html (9 August 2013).

[6] Mselle, L. J. and Kondo, T. S. (2012) 'Deploying computerbased learning under suboptimal conditions', International Conference on Internet Technology and Secure Transactions (ICITST), Heathrow, London, UK.

[7] Dhar, B. B. (2002) 'The Importance of ICT in Teaching: Is it growing?', Association of Indian Universities.

[8] William, P. L. 'Implementing technology in education: recent findings from research and evaluation studies', Far West Laboratory for Educational Research and Development, retrieved from http://www.wested.org/techpolicy/recapproach.html (30 June 2013).

[9] Ficheman I. K. and Lopes, R. D. (2008) 'Digital learning ecosystems: authoring, collaboration, immersion and mobility', IDC proceedings, Doctoral consortium, Chicago, IL, USA ACM.

[10] Bassili, J. N. (2006) "Promotion and prevention orientations in the choice to attend lectures or watch them online", Journal of Computer Assisted Learning 22: pp. 444 - 455.

[11] Blomkvist, S. (2002) 'The User as a personality, Using Personas as a tool for design', Position paper for the course workshop Theoretical perspectives in Human-Computer Interaction at IPLab, KTH.

[12] Greenberg, D. A. The impact of broadcast and streaming video in education, retrieved from www.cisco.com/en/us/solution (25 May 2013).

[13] http://www.necta.go.tz/matokeo_html_2013/CSEE_2012/ole vel.htm (8 September 2013).

[14] http://en.wikipedia.org/wiki/Offline_browsing (8 January 2014). 